\title{
Erratum to: Negotiating with the future: incorporating imaginary future generations into negotiations
}

\author{
Yoshio Kamijo $^{1,2}$ (1) $\cdot$ Asuka Komiya ${ }^{3}$ Nobuhiro Mifune ${ }^{1,2} \cdot$ Tatsuyoshi Saijo $^{1,2,4,5,6}$
}

Published online: 12 July 2017

(C) Springer Japan KK 2017

\section{Erratum to: Sustain Sci (2017) 12:409-420 DOI 10.1007/s11625-016-0419-8}

The article, Negotiating with the future: incorporating imaginary future generations into negotiations, written by Yoshio Kamijo, Asuka Komiya, Nobuhiro Mifune and Tatsuyoshi Saijo, was originally published Online First without open access. After publication in volume 12, issue 3, page 409-420 the author decided to opt for Open Choice and to make the article an open access publication.
Therefore, the copyright of the article has been changed to (C) The Author(s) 2017 and the article is forthwith distributed under the terms of the Creative Commons Attribution 4.0 International License (http://creativecommons. org/licenses/by/4.0/), which permits use, duplication, adaptation, distribution and reproduction in any medium or format, as long as you give appropriate credit to the original author(s) and the source, provide a link to the Creative Commons license, and indicate if changes were made.

The online version of the original article can be found under doi:10.1007/s11625-016-0419-8.

Yoshio Kamijo

yoshio.kamijo@gmail.com

1 School of Economics and Management, Kochi University of Technology, 2-22 Eikokuji-Cho, Kochi-Shi,

Kochi-Ken 780-8515, Japan

2 Research Center for Future Design, Kochi University of Technology, Kochi-Shi, Japan

3 School of Integrated Arts and Sciences, Hiroshima University, Higashihiroshima, Japan

4 Institute of Economic Research, Hitotsubashi University, Tokyo, Japan

5 Research Institute for Humanity and Nature, Kyoto, Japan

6 Urban Institute, Kyushu University, Fukuoka, Japan 